\title{
The Ethics of Control
}

\section{Chris Beckett}

In the flyer for the 'Ethics that Work' conference organized by this journal in November 2008, we raised the question as to whether teaching, writing and research about ethics in the social welfare field provided students with effective tools that they could 'actually use to guide their practice and help them resolve practice dilemmas'. Or was it possible, we asked, that professional education in reality offered 'little more than rhetorical devices - approved buzzwords and noble-sounding sentiments - that can be bolted on as necessary after the event, but have very little impact on actual practice decisions'?

Such concerns are quite widely shared. Eileen Gambrill, for instance, worries that 'lingering at the level of vague discourse - about empowerment for example which appeals to our emotions - lulls into abeyance our critical appraisal of what services clients receive (or do not), to what effect...' (2009, p. xviii). Russell Harbin contends that the code of practice of the National Association of Social Workers 'neglects the greatest range of actual cases of difficult moral choices' that social workers in practice are actually confronted with. As a result, he goes on to say, 'Not only will they be unable to fulfil the grandiose principles of their ethics codes, but they will typically have no categories to apply to the difficult moral choices that they have to make' (Harbin 1990, p. 540). In a similar vein, I myself previously argued here that recommendations of the kind contained in Lord Laming's report into the death of Victoria Climbie' (2003)

are in fact no more than 'wishlists' [which] pretend to offer solutions to a problem but in fact...ignore the single aspect of the problem that really is difficult for those on the ground, merely passing this back to them to struggle with. (Beckett 2007, p. 278)

One subject we seem to be particularly uncomfortable about in the social welfare field is the matter of control. I do not suggest that the control over people that is exercised by social welfare agencies is a secret, nor even that it is never discussed, but I do suggest that it is played down to a striking extent. For instance, given the extent to which my own profession of social work is engaged in exercising control over people, it is surprising what a small proportion of the profession's 'ethics talk' directly confronts the particular ethical issues that this raises. I recently asked a group of child and family social workers what percentage of their service users they thought were involuntary ones. Their short answer was 'most'. But although child and family social workers constitute a large part of the British social work workforce, and although other social work specialisms (notably mental health social work) also have quite explicit controlling functions, not to mention many subtle and implicit ones, it is surprising how little discussion there is, in our codes of ethics or in the standard texts used in social work education, of the particular ethical issues involved in working with people who have no choice but to work with us. I wonder whether the same is not also true of other human service professions?

The thinking behind this special issue, then, is that we in the social welfare field ought to engage more in thinking about the ethical principles that apply when we are involved in control. When is it morally justified to exercise control over others? What ethical principles should apply when we do? How do we square the exercise of control with our other commitments: to empower, to work in partnership, to promote self-determination? What effect does our ability to coerce have on our relationships with those with whom we work? What safeguards need to be put in place to prevent abuses? We may be uncomfortable about control. We might prefer not to be engaged in it. But if we think, teach and write about ethics in relation to a field where exercising control is part of the job, then we need to think, teach and write about the ethical issues that this raises, and not merely mention control and then move quickly on to more pleasant subjects. I do not pretend that this special issue covers all of the questions raised above in any sort of systematic way, but I hope that it will contribute to debate and open up more discussion of this subject in the future in the pages of Ethics \& Social Welfare and elsewhere. 
Each contributor has approached the topic of the special issue in a very different way. The following brief overview does not attempt to summarize the whole argument, or even necessarily the main issues offered by each, but aims to give at least a flavour of the content of the issue by picking out a few points from each contribution and noting a few common themes.

\section{Articles}

Kerstin Svensson, from the University of Lund in Sweden, drawing on previous work with Swedish volunteers and social workers, explores the ways in which workers reconcile their involvement in control with their own desire to see themselves as helpful and supportive. (She points out, incidentally, that there is a 'control' element in even the most apparently voluntary and supportive service.) She makes a series of points which link very closely to the rationale for this special issue as a whole. If control is 'ignored, separated and rewritten', she warns, or if we assume that our own goodness justifies controlling actions, 'there is a risk that social work will contain much more control than we are aware of' (p. 246).

Jim Campbell and Gavin Davidson, both from Queens University in Belfast, Northern Ireland, reflect on their experiences as Approved Social Workers under UK law with powers to apply for the compulsory detention of people defined as suffering from a 'mental disorder'. (As we'll see, two contributors to the 'Ethical Issues in Practice' section also draw on such experiences.) They explore the grounds on which this kind of coercion, and other more subtle forms, may be justified, and the proper basis on which decisions about it should be made. One of the points they make is that coercion exercised under formal legal powers can 'offer a greater degree of transparency and guidance for practitioners and clients' (p. 253) than informal coercion resulting from a combination of persuasion and threats in the guise of 'fair warning'. Another point is that how coercion is used and presented, as much as the simple fact of its use, may be an important factor in determining how damaging the experience is for those on the receiving end.

Donald Dickson, at Rutgers University, New Jersey, explores the coercive powers used in child protection work in the US context, where the legal situation varies from state to state. In particular, he considers the tensions, sometimes considerable, between what is legal and what is ethical in terms of the various professional codes of conduct. One of his concerns is that human service professionals may at times be pressured to take coercive courses of action which may be, or appear to be, legal but are unethical nevertheless. This is a particular danger, he suggests, because of the balance of power being typically hugely skewed against the service user, so that the professional is more likely to feel most pressure from other sources such as law enforcement agencies, rather than from family members. This dynamic is certainly one that is familiar to me from a UK context, and it is very similar to a dynamic eloquently described by Malcolm Kinney in the 'Ethical Issues in Practice' section, though Kinney is writing about a different jurisdiction and a different area of work. Dickson's observations on the misuse of so-called Voluntary Placement Agreements echo comments in the previous article on the dangers of informal forms of coercion that can be less transparent and less easy to challenge than more formal ones. They also remind us of the capacity for Orwellian doublespeak that exists in a social welfare system in which 'voluntary' may mean no choice at all.

Suzanne Fitzpatrick and Sarah Johnsen, at the Centre for Housing Policy at the University of York, discuss the coercive powers which in English law are used in an attempt to regulate or change 'street culture', and consider the ethical basis for the use of coercion in this context. They argue that such measures can sometimes be justified on social justice grounds. One interesting finding is that some of the homeless people who have been subjected to these coercive measures identify them as having turned out to be positive and helpful: a necessary jolt that became a catalyst for change. The application of coercive powers does inevitably create a crisis, a point at which things cannot go on exactly as before, and this can be positive. However, this is, of course, not necessarily the case, and Fitzpatrick and Johnsen do also identify ways in which the use of these powers can be unhelpful and indeed counterproductive. 
Even Nilssen and Nanna Kildal, both at the Stein Rokkan Centre for Social Studies, University of Bergen, conclude this section of the journal with some observations on a shift in Norwegian social policy towards a 'contractualist' approach based on supposed mutual obligations between the recipients of welfare provision and the state rather than on an absolute right to such provision. They unpick some of the philosophical assumptions that underlie this shift and question the validity of the idea of a contract in a situation in which there are such huge power differentials between the supposed parties to the agreement. I am uneasily reminded of my own experiences of the use of 'contracts' and 'agreements' in work with parents in the context of child and family social work in the United Kingdom, and I am reminded too of the heavy use of the word 'partnership' in current British discourse about social work and social welfare, a word which likewise seems to sweep huge power differentials under the carpet. Echoing themes I noted in previous articles about Orwellian language and the insidious nature of covert means of control, Nilssen and Kildal remind us that the state can easily increase its control over welfare recipients under the cloak of choice and empowerment. In social welfare, policies do not necessarily do what it says on the tin.

\section{Ethical Issues in Practice}

This section (edited for this issue, as for other issues, by Andrew Maynard and Beverley Burke) as usual includes articles written in a more personal and less formal style and from a perspective that is close to actual practice, whether from the perspective of service users or practitioners, but it continues with the 'ethics of control' theme.

Hazel Davies is a tireless and very experienced advocate for parents embroiled in child protection investigations and interventions in Essex in England. Her concern in this article is not so much to question the ethical basis for the existence of coercive powers but rather (echoing one of the points made by Campbell and Davidson) to explore the ethics of their actual use in practice, the desensitizing effect they can have on those who wield them, and the disabling effects they can have on those subjected to them. I was struck by the phrasing of her assertion (on p. 325) that control over others should only be exercised by those who themselves are 'in submission' to a coherent set of values, and not simply to the exigencies of an 'impersonal bureaucracy'. This idea of placing one's powers under submission to values is surely the core idea underlying the whole notion of professional ethics.

Malcolm Kinney and Chris Yianni are based, respectively, at Liverpool John Moores University and Manchester Metropolitan University in England. Both, like Campbell and Davidson earlier, draw on their experiences as Approved Social Workers under UK law. I myself have some limited experience of working in this role, as well as experience of exercising coercive powers under the 1989 Children Act and its predecessors, and I find aspects of Kinney's account hauntingly and uncomfortably familiar. He vividly describes the pressures and expectations (similar to those mentioned earlier by Donald Dickson) that can result in a professional feeling pressured into using coercive powers in a way that, deep down, he knows is not necessary and not in the best interests of his service user.

Chris Yianni also speaks of these pressures, though his paper is more of a tour of the competing issues and principles involved in these decisions. He finishes with a point that seems an appropriate ending for this special issue when he observes that it is too simple to see 'care' and 'control' as two opposite ends of a spectrum: 'the former is sometimes only facilitated by the use of the latter' (p. 000).

Care and control are very closely intertwined. Control can indeed itself be an expression of care rather than its opposite (think of a parent closely managing a small child by the side of a busy road), but it can also be oppressive and uncaring, as Hazel Davies describes. And as we have seen, this applies to the covert, implicit forms of control that we may exercise without even being aware of it ourselves, as well as to the more overt and explicit forms of control. Echoing Kerstin Svensson, I suggest we need to become more self-aware about control, however well intentioned, and more willing to ask ourselves questions about the ethical issues it raises. 


\section{References}

Beckett, C. (2007) 'The Reality Principle: Realism as an Ethical Obligation', Ethics \& Social Welfare, Vol. 1, no. 3, pp. 269_ 81.

Gambrill, E. (2009) 'Introduction', in Social Work Ethics, ed. E. Gambrill, Ashgate, Aldershot, pp. Xv_xxiv.

Harbin, R. (1990) 'The Artificial Duties of Contemporary Professionals: The Social Service Review Lecture', Social Service Review, Vol. 64, no. 4, pp. 528 _41.

Laming, Lord H. (2003) The Victoria Climbie' Inquiry, The Stationery Office, London. 